Article

\title{
Assessing healthcare workers' knowledge, emotions and perceived institutional preparedness about COVID-19 pandemic at Saudi hospitals in the early phase of the pandemic
}

\author{
Nashi Masnad Alreshidi, ${ }^{1}$ Hassan Kasim Haridi, ${ }^{2}$ Rana Alaseeri, ${ }^{1}$ Michelle Garcia, ${ }^{1}$ Fe Gaspar, ${ }^{1}$ \\ Laila Alrashidi ${ }^{1}$
}

${ }^{1}$ Nusing Administration, Ministry of Health, Hail Region, Hail

${ }^{2}$ Research Department, Ministry of Heath, Hail Region, Hail, Saudi Arabia

\begin{abstract}
Background: Coronavirus disease 2019 (COVID-19) pandemic extended to reach most countries in the globe during few months. Preparedness of healthcare institutions and healthcare workers (HCWs) are crucial for applying effective prevention and control measures. This study aimed to assess HCWs knowledge, emotions and perception of preparedness of their institutions towards COVID-19 pandemic.

Design: A cross-sectional, web-based survey was conducted among hospital HCWs in Saudi Arabia during April 27, 2020 to May 03, 2020.

Results: Overall, 1004 completed responses were received. The majority were females (78.8), nurses $(84.9 \%)$ at middle age 25-39 years (71.8\%). Among participants, $95.5 \%$ reported receiving training on safely use of personal protective equipment (PPE) and $94.9 \%$ did fit the test for N95 respirator. The participants possessed a fair knowledge about COVID-19 disease with a mean knowledge score $6.61 \pm 1.35$ points on a scale of 10 points. Most participants $(88.7 \%)$ were committed to continue work as a professional and ethical duty, however, $27.1 \%$ of them scored high on a negative emotional impact scale. Participants appreciated most aspects of institutional preparedness for COVID-19 pandemic; however, they were concerned with the continuous PPE supply. Factors that independently associated with good knowledge and negative emotional response were determined using multivariate logistic regression analysis.

Conclusions: Findings revealed fair knowledge about COVID-19 pandemic among HCWs in Saudi hospitals. Concerns and worries were expressed regard working with the highly infectious COVID-19 patients. Participants, appreciated most aspects of institutional preparedness, however they were concerned about the continuous availability and supply of PPE.
\end{abstract}

\section{Introduction}

Coronavirus disease (COVID-19) is described as an infectious disease caused by a virus, officially named as severe acute respiratory syndrome coronavirus 2 (SARS-CoV-2) by the World Health Organization (WHO). ${ }^{1}$ The virus caused an epidemic started in December 2019 in Wuhan, China, and continue to spread rapidly reaching to almost all countries worldwide claiming many lives of healthcare workers as the front liners. ${ }^{2}$ Within three months of discovering this virus the spread rate, reach up to 2,160,207 confirmed cases with 146,088 confirmed deaths of coronavirus disease worldwide (WHO) with at least 8274 cases and 92 reported deaths in Saudi Arabia, ${ }^{3}$ figures escalating every day, even every hour, so far.

Unprecedented measures have been adopted worldwide to control the transmission of COVID-19 plague including the suspension of public transportation, industries, implementation of isolation precautions, social distancing and care of infected and suspected cases.

Knowledge about it is still limited and there is no exact therapeutic regimen, neither vaccine yet available at present. ${ }^{4}$ Most studies have been investigating on the virus characteristics, its epidemiology, therapeutic regimen, vaccine trials, but little about healthcare workers' (HCWs) knowledge and concerns as well as institutional preparedness on handling the sudden surge which created a devastating effect to the health care system even to the most advanced countries in Europe, America and Asia. Regardless of adequate knowledge, HCWs are still anxious of becoming infected with the disease, specially physicians and nurses. Daily routine procedures pose them at risky situations and become infected if they are not careful enough. ${ }^{5}$ Concerns of HCWs' regard the possibility of infecting their family members with the virus is another major contributory factors for their anxiety. ${ }^{6}$

In order to address the current challenges facing health work-

Significance for public health

emergencies, such as communicable disease epidemics. The current and rapidly evolving nature of the COVID-19 pandemic requires hospitals to have in place all essential preparedness measures. Preparedness of healthcare institutions and healthcare workers (HCWs) are crucial for applying effective prevention and control measures. Among important points, are adapting preparedness plans in response to monitoring and conducting situation analysis surveys, especially among healthcare workers to address their views about the current challenges facing their institutions and factors influencing their preparedness. Early assessment HCWs' factual knowledge, emotions and concerns, and their perception regards preparedness of their institutions towards COVID-19 pandemic give insight and provide information to the hospital administration and policy makers to be sensitively responsive to the presented challenges and guide effective interventions. 
ers and institutions in Saudi Arabia, this investigation was carried out as a situation analysis to assess the current knowledge, emotion of HCW's and their views regard preparedness of their institutions at the time of the survey.

\section{Design and Methods}

\section{Study design and participants}

This was a cross-sectional, study carried out in Saudi Arabia. A convenience sample was used to recruit the study participants. The target population were health-care workers in hospitals with inclusion criteria of being directly or indirectly dealing with probable or definite COVID-19 patients and have no administrative responsibilities at the time of the survey. Healthcare workers are termed in this study as physicians, nurses, respiratory therapists, pharmacist and radiologist and other potential health practitioners involve in patients' care during the pandemic period from both government and private hospitals.

\section{Study tool}

The survey tool was an online self-reported questionnaire developed by the investigators guided by CDC comprehensive hospital preparedness checklist for coronavirus disease $2019^{7}$ and ASHP COVID-19 pandemic assessment tool for health system pharmacist ${ }^{8}$ and those used by similar previous studies. ${ }^{5,9}$

The questionnaire contained the following four sections. The first section composed of a set of questions aimed to determine the sociodemographic and workplace characteristics, which includes profession, age, gender, educational attainment, having children, working hours, place of work and a question on whether they deal with coronavirus patient. The second section contained 10 questions to assess the Covid-19 disease background, mode of transmission, prevention, infection control measures, and vulnerable persons at high risk for severe illness from COVID-19. The third section contained 10 statements to examine the emotional impact of the current pandemic. The last part was devoted to HCWs' perception about institutional preparedness including 4 divisions: planning and decision making (3 items), supplies and resources (2 items), education and training (3 items) and facility communications (7 items).

Face and content validity of the questionnaire were reviewed, by a panel of 4 experts in the field of public health, infection control, occupational health and quality. Their recommendations were taken in consideration in finalizing the questionnaire content. A pilot study was done on 20 eligible HCWs (not included in the final sample) were carried out before commencing the study, accordingly, the questionnaire was adapted to its final form. The final data collection tool of the study possessed acceptable reliability (Cronbach's $\alpha$ internal consistency coefficient was 0.895 ).

\section{Study procedures}

Upon procurement of the ethical approval, communication was established with all Regional Chief Nurses in all Health Directorates in the country $(\mathrm{n}=20)$, of them 17 positively replied to participate, yielding $85 \%$ response rate. An introduction to the survey objectives and a link of the questionnaire was sent to the designated coordinator in participated region with thorough instruction regarding inclusion and exclusion criteria of participants. Anonymity, confidentiality of information and voluntary participation in the study were emphasized. They were asked to encourage the target staff in their hospitals to roll out the survey to as many colleagues as possible within one-week period as the survey will document a temporal situation of HCWs and institutions in Saudi Arabia. Coordinators were asked to send the link of the survey questionnaire to the work WhatsApp communication groups in their hospitals and kindly to send a reminder for them twice during the survey time. A beginning paragraph introducing to the study objectives and eligibility for participation was included as a start for the survey questionnaire. The link of the survey was kept open accepting responses from April 27, 2020 to May 03, 2020 resulting to 1004 completed responses after filtering to exclude non-applicable participants and incomplete responses.

Table 1. Participants' background information ( $\mathrm{n}=1004)$.

\begin{tabular}{|c|c|}
\hline Characteristic & n $(\%)$ \\
\hline $\begin{array}{l}\text { Age in years } \\
\quad>25 \\
\quad 25-29 \\
30-39 \\
\quad \geq 40\end{array}$ & $\begin{array}{l}113(11.3) \\
474(47.2) \\
247(24.6) \\
170(16.9)\end{array}$ \\
\hline $\begin{array}{l}\text { Gender } \\
\text { Male } \\
\text { Female } \\
\end{array}$ & $\begin{array}{l}213(21.2) \\
791(78.8)\end{array}$ \\
\hline $\begin{array}{l}\text { Have children } \\
\text { Yes } \\
\text { No }\end{array}$ & $\begin{array}{l}476(47.4) \\
528(52.6)\end{array}$ \\
\hline $\begin{array}{l}\text { Level of education } \\
\text { Diploma } \\
\text { Bachlor } \\
\text { Post graduate } \\
\end{array}$ & $\begin{array}{c}94(9.4) \\
752(74.9) \\
158(15.8)\end{array}$ \\
\hline $\begin{array}{l}\text { Profession } \\
\text { Physician } \\
\text { Nurse } \\
\text { Other staff }\end{array}$ & $\begin{array}{c}116(11.6) \\
852(84.9) \\
36(3.5)\end{array}$ \\
\hline $\begin{array}{l}\text { Work experience in years } \\
\quad<5 \\
\quad 5-10 \\
11-20 \\
>20\end{array}$ & $\begin{array}{c}333(33.2) \\
425(42.3) \\
205(20.4) \\
41(4.1)\end{array}$ \\
\hline $\begin{array}{c}\text { Working hours } \\
8 \text { hours } \\
12 \text { hours }\end{array}$ & $\begin{array}{l}724(72.1) \\
280(27.9)\end{array}$ \\
\hline $\begin{array}{l}\text { Place of work } \\
\text { ER } \\
\text { OPD } \\
\text { Medical-Surgical Unit } \\
\text { ICU/PICU/NICU/CCU } \\
\text { Other work Places }\end{array}$ & $\begin{array}{ll}287 & (28.6) \\
100 & (10.0) \\
142 & (14.2) \\
149 & (14.9) \\
32.6 & (32.3)\end{array}$ \\
\hline
\end{tabular}

Place of work with isolation

Yes $142(14.1)$

No $\quad 862(85.9)$

$\begin{array}{ll}\text { Currently dealing with COVID-19 virus } & \\ \text { Yes } & 231(23.0) \\ \text { No } & 773(77.0)\end{array}$

Trained on safely donning and doffing PPE in the previous year

Yes 959 (95.5)

No 45 (4.5)

Did fit the test for respirator within the previous year

Yes

$393(94.9)$

No 51 (5.1), 


\section{Statistical analysis}

Data analysis was carried out using IBM SPSS ver. 23.0 (IBM Corp., Armonk, NY, USA). Descriptive statistics were conducted to present demographics, knowledge level of staff, emotional impact and hospital facility preparedness. Frequencies and percentages, means and standard deviations were used to summarize data. Continuous variables were compared with the use of the Student's $t$-test or Mann-Whitney test. The chi-square test was used to compare categorical variables. For knowledge questions, a scoring system was assigned for the included items: 1, correct response; 0 , incorrect and 'do not know' responses. Responses for the emotional impact of the pandemic crisis statements, a scoring system was assigned for the included items: 0 , for 'No; 1 , for 'Yes. A scale was created for the knowledge domain with points attributed for each question, with maximum score of 10 points. Another scale for the negative emotional impact of the pandemic crises was created to include 7 statements (No. 2, 3, 6,7,8,9 and 10), with maximum negative score of 7 points. To confirm whether the participants had good knowledge a cut-off point of 7 or more on the knowledge scale was considered to indicate good knowledge. Indication of the exaggerated negative emotional impact of the pandemic crises on the participants was determined at cut-off point of 4 or more on the negative emotional impact sale.

To determine the association between outcomes of good COVID-19 knowledge and the exaggerated negative emotional impact of the pandemic as an outcome variables, logistic regres- sion analysis was performed for each. Good knowledge was analyzed against the possible variables that might affect knowledge level including demographic, experience, professional and workplace characteristics, sources of knowledge, training and emotional impact of the pandemic. The exaggerated negative emotional impact of the pandemic crises on the participants was analyzed against the possible variables that might affect the emotional impact including demographic, experience, professional and workplace characteristics, knowledge level, training received, institutional polices regard the pandemic. Any variable resulting in a value $\leq 0.25$ in the bivariate analysis was included in the multivariable model. The variables included in each model were then subjected to a backward multivariate logistic regression analysis to control the effect of the confounders and determine the significant independent predictors. Results of the logistic regression analysis are presented as Odds Ratios (ORs) and 95\% confidence intervals (CIs). A two-sided p-value for all tests $<0.05$ was considered significant.

\section{Results}

Table 1 recorded the background information of the study participants. Exactly 1004 HCW's participated in the study. Majority of the participants $(587 ; 58.5 \%)$ were $\leq 30$ years; 791 (78.8\%) were

Table 2. Knowledge of healthcare workers about the emerging Corona virus disease (COVID-19) in Saudi Arabia, 2020 (n=1004).

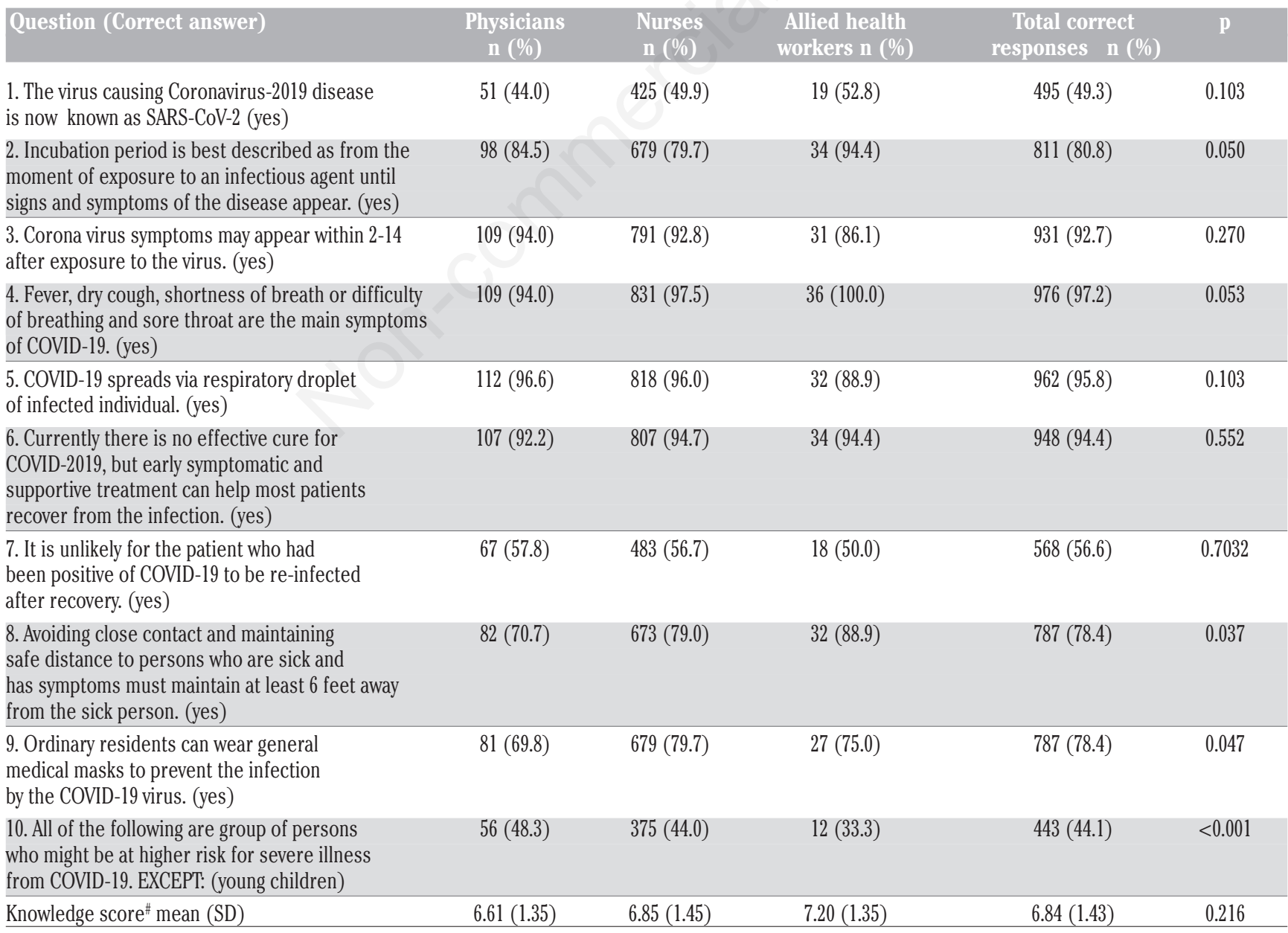

\#Knowledge score: with maximum 10 points. 
male and $528(52.6 \%)$ have children. It is apparent from this table, exactly 752 (74.9\%) obtained bachelors' degree, and $852(84.9 \%)$ were nurses, $116(11.6 \%)$ physician and $36(3.5 \%)$ from other staff. In view of work experience most had 5-10 years' experience 425 $(42.3 \%)$ and the least is $>20$ years $41(4.1 \%)$. The majority 724 (72.1\%) were working for 8 hours, while 280 (27.9\%) were working for 12 hours. A considerable number 287 (28.6\%) of the respondents were working in emergency departments, with nearly the same percentage from Medical-Surgical unit with isolation and ICU/PICU/NICU/CCU about $142(14.2 \%)$ to 149 (14.9\%). Majority were not dealing with confirmed COVID-19 cases 773 (77\%), 959 (95.5\%) have proper training on donning and doffing PPE in the previous year and 393 (94.9\%) had undergone respiratory fit test.

Table 2 presents summary statistics of participants' correct responses about COVID-19 disease. The mean COVID-19 total knowledge score was $6.84 \pm 1.43$ points, which indicates $68.4 \%$ correct rate on the knowledge test, with no statistically significant difference between the professional groups $(\mathrm{p}=0.216)$. A knowledge gap among participants was there when asked about the were virus causing coronavirus disease 2019 (49.3\%) and regarding individuals at high risk for severe illness (44.1\%) Nonetheless, respondents were abreast about the incubation period of the disease $(80.8 \%)$, well-informed on the main symptoms of COVID-19 (97.2\%), mode of transmission $(95.8 \%)$ and known to them that there is still no specific cure $(94.4 \%)$.

Table 3 depicts the psychological impact of COVID-19 to HCW's. Out of 1004 participants $891(88.7 \%)$ had a positive feeling toward their job and $631(62.8 \%)$ are expecting a financial compensation during the outbreak. Following the negative feelings, $495(49.3 \%)$ were nervous or scared, 429 (42.7) felt overtime is unacceptable, $219(21.8 \%)$ plans to quit their job, $534(53.2 \%)$ chose not to deal with COVID-19 cases, 188 (18\%) would quit their job if an outbreak recurs, $351(35.0 \%)$ felt they were called sick and 292 (29.1\%) had been ones called as sick person. Overall, the mean score of the 7 indicators of negative emotional impact of COVID-19 among the participants was $2.50 \pm 2.01$ on a scale of 7 points, which indicate an overall negative feeling (35.7\%) among participants which is not high.

Table 4 expresses the perception of HCW's on the prepared- ness of their facility to combat COVID-19, four categories assessed. First, facility communication appeared rated at high point ranging from $(86.1 \%-93.7 \%)$ second is education and training of staff on proper use of PPE $(81.5 \%-95.8 \%)$ third is structure for planning and decision making ( $81.9 \%$ to $94.9 \%$ ) lastly, the lowest rated category is on supplies and resources of PPE $(58.7 \%$ to $68.5 \%)$.

Table 5 depicts the results of the adjusted multivariate logistic regression analysis that find out factors that independently associated with good knowledge (Model 1) and exaggerated negative emotional responses among the participants (Model 2) during COVID-19 pandemic period.

Adequate knowledge was independently associated with older age (OR, 2.13; 95\% CI: 1.03-4.40; $\mathrm{p}=0.041)$ for age group 30-39 years, and (OR, 4.21; 95\% CI: 1.95-9.08; $<<0.001)$ for the age group ( $\geq 40$ years) compared to youngers ( $<25$ years), female gender (OR, 2.50; 95\% CI: 1.48-4.25; $<<0.001$ ), place of work having an isolation room with HCWs directly dealing with COVID-19 patients (OR, 1.89; 95\% CI: 1.21-2.97; $\mathrm{p}=0.006$ ), and negative feeling score (OR, 1.30; 95\% CI: 1.18-1.44; $\mathrm{p}<0.001)$.

The likelihood of HCW's being negative emotionally responsive during COVID-19 pandemic was independently positively associated with dealing with COVID-19 patients (OR, 1.63; 95\% CI: 1.19-2.24; $\mathrm{p}=0.002$ ), working in designated area with isolation room (OR, 1.89; 95\% CI: 1.30-2.74; $\mathrm{p}<0.001$ ) and longer work experience $>10 / \leq 10$ years (OR, $1.53 ; 95 \%$ CI: $1.10-2.12 ; p=0.11$ ). On the other hand, presence of hospital policy to address employees with suspect or known exposure to COVID-19 virus (OR, 0.59; 95\% CI: $0.40-0.87 ; \mathrm{p}=0.008)$, and implementation of respiratory triage (OR, $0.47 ; 95 \% \mathrm{CI}: 0.26-0.86 ; \mathrm{p}=0.14$ ), were factors independently reduced the negative emotional response between HCWs.

\section{Discussion}

COVID-19 pandemic has overwhelmed healthcare systems, healthcare workers, and exhausted resources, revealing how much preparedness impacted healthcare institutions in handling this pan-

Table 3. Emotional effect of COVID-19 pandemic on healthcare workers in Saudi Arabia, 2020 (n=1004).

\begin{tabular}{|c|c|c|c|c|c|}
\hline Staff feeling & $\begin{array}{l}\text { Physicians n } \\
(\%)\end{array}$ & $\begin{array}{l}\text { Nurses } \\
\text { n }(\%)\end{array}$ & $\begin{array}{l}\text { Allied health } \\
\text { workers n (\%) }\end{array}$ & $\begin{array}{c}\text { Total agreed } \\
\text { responses } \\
\text { n (\%) }\end{array}$ & p \\
\hline $\begin{array}{l}\text { 1. You felt that you had to do your job as it was your } \\
\text { professional and ethical duty. }\end{array}$ & $90(77.6)$ & $769(90.3)$ & $32(88.9)$ & $891(88.7)$ & $<0.001$ \\
\hline 2. You felt nervous and scared. & $27(23.3)$ & $449(52.7)$ & $19(52.8)$ & $495(49.3)$ & $<0.001$ \\
\hline 3. You were unhappy to do overtime. & $27(23.3)$ & $389(45.7)$ & $13(36.1)$ & $429(42.7)$ & $<0.001$ \\
\hline $\begin{array}{l}\text { 4. You receive special recognition for your job } \\
\text { by the hospital administration. }\end{array}$ & $54(46.6)$ & $268(31.5)$ & $29(80.6)$ & $351(35.0)$ & $<0.001$ \\
\hline 5. You expect financial compensation during the outbreak. & $49(42.2)$ & $560(65.7)$ & $22(61.1)$ & $631(62.8)$ & $<0.001$ \\
\hline 6. You thought of quitting your job. & $25(21.6)$ & $182(21.4)$ & $12(33.3)$ & $219(21.8)$ & 0.234 \\
\hline $\begin{array}{l}\text { 7. If optional, you will not choose the unit where } \\
\text { you will be exposed to COVID-19. }\end{array}$ & $45(38.8)$ & $466(54.7)$ & $23(63.9)$ & $534(53.2)$ & 0.002 \\
\hline 8. You would quit your job if COVID-19 outbreak recurred. & $24(20.7)$ & $150(17.6)$ & $14(38.9)$ & $188(18.7)$ & 0.005 \\
\hline 9. You thought of calling in sick. & $38(32.8)$ & $298(35.0)$ & 15 (41.7) & $351(35.0)$ & 0.619 \\
\hline 10. You called in sick at least once. & $34(29.3)$ & $248(29.1)$ & $10(27.8)$ & $292(29.1)$ & 0.984 \\
\hline Negative feeling score\# mean (SD) & $1.90(1.97)$ & $2.56(1.99)$ & $2.94(2.20)$ & $2.50(2.01)$ & $<0.001$ \\
\hline
\end{tabular}

\#Negative feeling score: Composed of statements: 2,3,6,7,8,9 and 10, with maximum 7 points. 
demic. This situation is unprecedented and came without any similar near experience. Ongoing assessment of preparedness of healthcare institutions is crucial in effectively dealing with a rapidly changing situation and fixing any emerging problem. Hence, we conducted this study in Saudi Arabia as a situation analysis to assess knowledge, concerns of the HCWs and their views regard preparedness of their institutions in order to provide an evidence based insight for policy makers and health management. Overall, participants of the study perceived good institutional preparedness towards dealing with the current COVID-19 pandemic. Out of 14

Table 4. Perceptions of the healthcare workers about the preparedness of their health facility on COVID-19 pandemic in Saudi Arabia, $2020(n=1004)$.

\begin{tabular}{|c|c|c|}
\hline Criteria & Yes n (\%) & No n $(\%)$ \\
\hline \multicolumn{3}{|l|}{ Structure for planning and decision making } \\
\hline Has your hospital instituted travel/exposure history screening for all patients with fever and /or respiratory symptoms? & $953(94.9)$ & $51(5.1)$ \\
\hline Is there an airborne infection isolation rooms (negative pressure) available in your unit? & $817(81.9)$ & $181(18.1)$ \\
\hline \multicolumn{3}{|l|}{ Supplies and resources } \\
\hline Sufficient PPE for airborne precaution in your unit? & $686(68.5)$ & $315(31.5)$ \\
\hline $\begin{array}{l}\text { Does your hospital have sufficient PPE stock on hand to protect the staff if there is rapid surge in patients } \\
\text { with possible covid19 infection? }\end{array}$ & $588(58.7)$ & $413(41.3)$ \\
\hline \multicolumn{3}{|l|}{ Education and training } \\
\hline Have you been trained on safely donning and doffing PPE in previous year? & $959(95.8)$ & $42(4.2)$ \\
\hline Have you been fit test for a respirator within the previous year? & $911(90.9)$ & $91(9.1)$ \\
\hline $\begin{array}{l}\text { Does your hospital have an overflow plan to allocate trained staff enable safe care provision to patients } \\
\text { in isolation for possible COVID-19 positive? }\end{array}$ & $814(81.5)$ & $185(18.5)$ \\
\hline \multicolumn{3}{|l|}{ Facility communications } \\
\hline $\begin{array}{l}\text { Has your hospital implemented information campaign or other secondary screening isolation to ask patient with } \\
\text { symptoms and travel/exposure history to call ahead to the hospital/clinic before coming in? }\end{array}$ & $891(88.7)$ & $113(11.3)$ \\
\hline Does your hospital have policy to address employees with suspected or known exposure to the SAR-Cov-2 & $864(86.1)$ & $140(13.9)$ \\
\hline $\begin{array}{l}\text { There are identified points of contact for COVID-19 pandemic planning resources within the institution } \\
\text { or region or country as a whole. }\end{array}$ & $941(93.7)$ & $63(6.3)$ \\
\hline The hospital has a means or plans for communication with patient and their family. & $912(90.8)$ & $92(9.2)$ \\
\hline Communication is open for any coordination related to resources demand and acquisition during pandemic surge. & $918(91.4)$ & $86(8.6)$ \\
\hline $\begin{array}{l}\text { The facility educated its staff to channel all public communications through public information } \\
\text { or institutional spokesperson. }\end{array}$ & $892(88.8)$ & $112(11.2)$ \\
\hline $\begin{array}{l}\text { Participation of hospital administration in identification of communication needs and methods those are appropriate } \\
\text { for all individuals including those with disabilities and limited language proficiency. }\end{array}$ & $891(88.7)$ & $113(11.3)$ \\
\hline
\end{tabular}

Table 5. Adjusted multivariate logistic regression analyses for demographic and potential factors associated with good knowledge and negative emotional reactions among healthcare workers during COVID-19 pandemic period in Saudi Arabia, 2020.

\begin{tabular}{|c|c|c|c|c|c|c|}
\hline Term & $\mathrm{aOR}$ & $95 \%$ CI & Coefficient & SE & Z-statistic & 1 \\
\hline
\end{tabular}

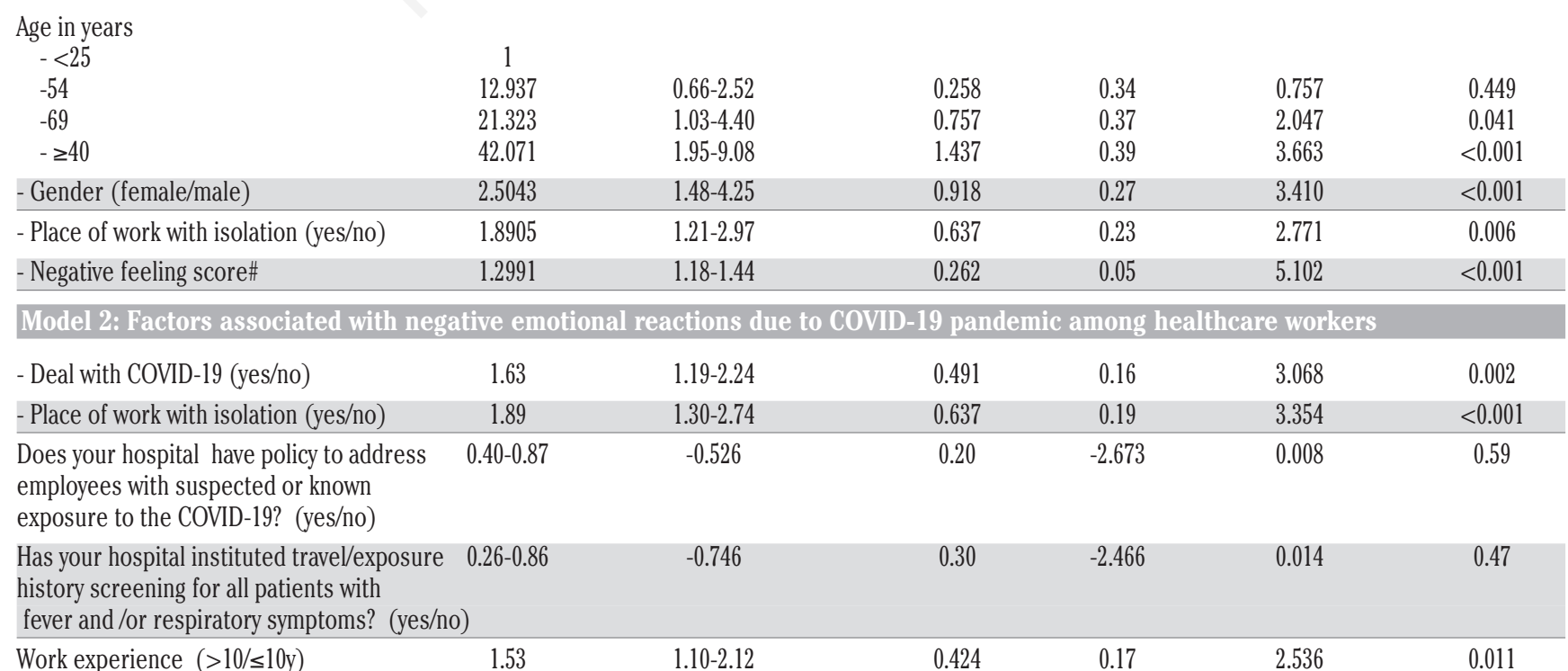


criteria confirming institutional preparedness, participants perceived positively 12 criteria, with agreement ranged between $81.9 \%$ to $95.8 \%$, however, they were concerned about the other two indicators related to sufficiency of PPE supply and stock on hand coping with the rapid surge in COVID-19 patients, with just $68.5 \%$ and $58.7 \%$ respectively agreed about its sufficiency. These concerns appear to be universal among HCWs in all affected countries, arising from heavier use of PPE than normal which may lead to the shortage perceived and that the lack of a robust supply chain may delaying restocking PPE needed to protect staff. ${ }^{10,11}$

Our study uncovered a substantial knowledge gab about COVID-19 disease among the participant HCWs, regardless of a fair $(68.4 \%)$ overall knowledge score attained. This knowledge level was comparable to reports came from some countries, ${ }^{12}$ yet, it was lower than higher scores reported by some others. ${ }^{5,8}$ Worth noting that comparisons of knowledge reported in different studied is difficult and should be taken with care, due to different sets of knowledge questions asked, different phases of the epidemic when studies were carried out, and differences in characteristics of the surveyed population.

A knowledge gab was found among the participants in our study; only, about half (49.3\%) recognized that the virus causing COVID-19 is SARS-COV-2 virus and just $44.1 \%$ of them can exclude children from the well-known groups at higher risk of complications. Otherwise, the participants knew the cardinal symptoms of the disease $(97.2 \%)$, incubation period of the virus $(92.7 \%)$, mode of transmission of the virus $(95.8 \%)$, that no specific treatment available so far $(94.4 \%)$, and the safe distance to minimize exposure to infection (78.4\%).

Good knowledge among our study participants was independently associated with being in workplace directly dealing with COVID-19 patients as well as those who were more worried. HCWs in isolation units for COVID-19 cases were about two times more likely to have good knowledge compared to other HCWs (OR 1.89, 1.21-2.97; $\mathrm{p}=0.006$ ). Moreover, HCWs who were more worried of being caring for COVID-19 patients, were independently more likely to have good knowledge compared to other HCWs (OR, 1.30; 95\% CI: 1.18-1.44; p<0.001).

Possible explanation, is that being in a risky situation where infection with COVID-19 virus is likely, provokes information seeking behavior among HCWs to better understand aspects of the risk, like, characteristics of causative agent, evaluation of self-susceptibility and vulnerability, and to evaluate efficacy of the available preventive measures. ${ }^{13}$

Adequate knowledge among participants in our study was independently associated with older age with an escalating trend (OR, 1.29; 95\% CI: 0.66-2.52; $p=0.45$ ) for age group $25-29$ years (OR, 2.13; 95\% CI: 1.03-4.40; $\mathrm{p}=0.041$ ) for age group 30-39 years, and (OR, 4.21; 95\% CI: 1.95-9.08; $\mathrm{p}<0.001)$ for the age group ( $\geq 40$ years) compared to youngers $(<25$ years). This apparently logic, since that older age is an important risk factor for severe morbidity and mortality from COVID-19 viral infection, ${ }^{14}$ so that more active information seeking among them about the disease logically occurs.

COVID-19 pandemic possessed an emotional impact on the study participants; $49.3 \%$ were anxious and scared, $42.7 \%$ were hesitant to work overtime and $21.8 \%$ thought of quitting their job. Experience from this pandemic ${ }^{15}$ and previous outbreaks and epidemics of various infectious diseases,,${ }^{9,13,16-18}$ has also showed to cause a significant psychological impact on HCWs.

In our analysis, two factors were identified as having an independent association with the exaggerated negative emotional feel- ing among the participants in our study: i) working in high risk unit where COVID-19 patients are isolated; ii) dealing directly with COVID-19 patients. This indicates a high risk perception and concern among this group of HCWs, who are really at higher risk of acquiring infection during their work, compared to other groups of HCWs, especially, when they overwhelmed with high work load, prolonged work time, and perhaps, inconsistent PPE supply and other infection prevention and control measures, combined with no proved specific treatment or preventive vaccine. On the other hand, two institutional factors were found to be independently helped to reduce the exaggerated negative emotional effect among the participants: i) the hospital have a policy to address employees with suspected or known exposure to the COVID-19; and ii) the hospital instituted travel/exposure history screening for all patients with fever and/or respiratory symptoms. This implies the importance of institutional measures/responses in satisfying HCWs and mitigating their anxiety. The situation of the current pandemic is unprecedented and came without any playbook. Health care leaders must take a collaborative and iterative approach to figure it out. ${ }^{19}$ Efforts should be directed to empower HCWs with good training, psychological support, providing clear and updated policies/guidelines, apply effective plans for infection prevention and control, provide and maintain PPE and other infection control logistics and ensuring good occupational medical and social care if they fall sick. Trust in institutional plans and measures found to be of paramount impact on $\mathrm{HCWs}{ }^{20}$

\section{Limitations}

The study has a number of inherent limitations. Firstly, it is a cross-sectional study, so that, relationships between the predictor variables and the dependent variables (HCWs knowledge and emotional response) can only be described as general associations rather than causal relationships. Secondly, this is an online survey, responses mainly depend upon honesty and partly affected by recall ability and thus may subject to recall bias. Being an online survey, so that responses almost came from motivated subjects and potential sample clustering might also limit the generalizability of the study. Despite the identified limitations, these results contribute to the information relating to the overwhelming health problem faced by HCWs not only in Saudi Arabia, but also at the global level.

\section{Conclusion}

Findings of the present study revealed fair knowledge about COVID-19 pandemic among HCWs in Saudi hospitals and their commitment to continue work as a professional and ethical duty. Concerns and worries expressed regard working directly with the highly infectious COVID-19 patients. Participants appreciated most aspects of institutional preparedness towards better dealing with the pandemic, especially, education and training, planning and decision making, and facility communication however, they need to be sure of the continuous supply and stock availability of PPE. This investigation gave insight to policy makers and health management to deal with HCWs concerns and demands, adapting training programs to suit HCWs needs and to sensitively adapt health management system to cope with the rapidly changing and challenging health problem with high public concern and impact. 
Correspondence: Nashi Masnad Alreshidi, Nursing Administration, Ministry of Health, Hail Region, Health Affairs, Governmental Complex, Hail, Saudi Arabia. Tel. +966.5048183321.

E-mail.: nmalreshidi@moh.gov.sa

Key words: COVID-19; knowledge; emotions; healthcare workers; institutional preparedness; Saudi Arabia.

Contributions: All authors participated in conducting the survey and writing the manuscript. NA, conceived the idea and study design; $\mathrm{HH}$, data analysis, interpretation of results, study revision; NA, RA, MG, FG, LA participated in development of the data collection tool. All authors critically revised, and approved the final version of the manuscript.

Acknowledgements: We would like to thank all healthcare works who is participated in this survey and who assisted to make this study possible. This study would have had not been possible without their participation and assistance.

Conflict of interest: The authors declare that they have no competing interests, and all authors confirm accuracy.

Ethics approval and consent to participate: The protocol of the study was reviewed and approved by the Regional Bioethics Committee of the General Directorate of Health Affairs, Hail region, with the approval number 2020/17 dated April 26, 2020. Online informed consent was obtained from all participants with full disclosure and explanation of the purpose and procedures of this study. Participants were guaranteed anonymity confidentiality of the responses and voluntary participation and they can withdraw consent for any reason and any time, simply by not completing the questionnaire.

Consent for publication: Not applicable.

Availability of data and materials: The data used to support the findings of this study are available from the corresponding author upon request.

Received for publication: 10 September 2020

Accepted for publication: 8 October 2020 .

oCopyright: the Author(s), 2020

Licensee PAGEPress, Italy

Journal of Public Health Research 2020;9:1936

doi:10.4081/jphr:2020.1936

This work is licensed under a Creative Commons Attribution

NonCommercial 4.0 License (CC BY-NC 4.0).

\section{References}

1. WHO. Naming the corona virus disease (COVID-19) and the virus that causes it. 2020. Accessed May 6, 2020. Available from: https://www.who.int/emergencies/diseases/novel-coronavirus-2019/technical-guidance/naming-the-coronavirus-disease-(covid-2019)-and-the-virus-that-causes-it

2. Zhong BL, Luo W, Li HM, et al. Knowledge, attitudes, and practices towards COVID-19 among Chinese residents during the rapid rise period of the COVID-19 outbreak: a quick online cross-sectional survey. Int J Biol Sci 2020;16:1745-52. doi: $10.7150 / \mathrm{ijbs} .45221$

3. Saudi Gazette [Internet]. Saudi Gazette report April 18, 2020 03:00 H. Accessed May 6, 2020. Available from: https://saudigazette.com.sa/article/592035
4. Albarrak AI, Mohammed R, Al Elayan A, et al. Middle East Respiratory Syndrome (MERS): Comparing the knowledge, attitude and practices of different health care workers. J Infect Public Health 2019;S1876-0341(19)30239-4. doi: 10.1016/j.jiph.2019.06.029

5. Zhang M, Zhou M, Tang F, et al. Knowledge, attitude, and practice regarding COVID-19 among healthcare workers in Henan, China. J Hosp Infect 2020;105:183-7. doi: 10.1016/j.jhin.2020.04.012

6. Huynh G, Nguyen TN, Tran VK, et al. Knowledge and attitude toward COVID-19 among healthcare workers at District 2 Hospital, Ho Chi Minh City. Asian Pac J Trop Med 2020;13: 260-5.

7. Center for Disease Control and Prevention. Coronavirus disease 2019. Comprehensive hospital preparedness checklist for coronavirus disease 2019. March 25, 2020. Available from: https:/www.cdc.gov/coronavirus/2019-ncov/hcp/hcp-hospital-checklist.html. The tool available from: https://www.cdc. gov/coronavirus/2019-ncov/downloads/HCW_Checklist_ 508.pdf

8. American Society of Health System Pharmacist. ASHP COVID-19 Pandemic assessment tool for health system pharmacist. Accessed 24 March, 2020Available form: https://www.ashp.org/-/media/assets/pharmacy-practice/ resource-centers/Coronavirus/docs/ASHP COVID19 AssessmentTool.ashx?loc=ashphero3-covid19assessmenttool03182020

9. Khalid I, Khalid TJ, Qabajah MR, et al. Healthcare workers emotions, perceived stressors and coping strategies during a MERS-CoV outbreak. Clin Med Res 2016;14:7-14. doi: $10.3121 / \mathrm{cmr} .2016 .1303$

10. U.S. Department of Health and Human Services. Hospital experiences responding to the COVID-19 pandemic: Results of a National pulse survey March 23-27, 2020. Accessed June 2, 2020. Available from: https://www.oig.hhs.gov/oei/reports/oei-06-20-00300.pdf

11. WHO. Shortage of personal protective equipment endangering health workers worldwide. Accessed June 2, 2020. Available from: https://www.who.int/news-room/detail/03-03-2020shortage-of-personal-protective-equipment-endangeringhealth-workers-worldwide

12. Olum R, Chekwech G, Wekha G, et al. Coronavirus disease2019: Knowledge, attitude, and practices of health care workers at Makerere University Teaching Hospitals, Uganda. Front Public Health 2020;8:181. doi: 10.3389/fpubh.2020.00181

13. Hassan Kasim Haridi, Abdulellah Al-Fatani, Ayman Esam Yamani. Assessment of Ebola Virus Disease (EVD) outbreak emergency response among Healthcare Providers (HCPs) in Mena Emergency Hospital during Hajj Season 1435. The Scientific Bulletin, Om Al-Qura University Makkah, Saudi Arabia. Accessed May 22, 2020. Available from: https://drive.uqu.edu.sa/_hajj/files/multaqa/143918_English.p df\#page $=30$.

14. Leung C. Risk factors for predicting mortality in elderly patients with COVID-19: A review of clinical data in China. Mech Ageing Dev 2020;188:111255. doi: 10.1016/j.mad. 2020.111255

15. Kang L, Li Y, Hu S, et al. The mental health of medical workers in Wuhan, China dealing with the 2019 novel coronavirus. Lancet Psychiatry 2020;7:e14. doi: 10.1016/S22150366(20)30047-X

16. Chong MY, Wang WC, Hsieh WC, et al. Psychological impact of severe acute respiratory syndrome on health workers in a tertiary hospital. Br J Psychiatry 2004;185:127-33. doi: 
10.1192/bjp.185.2.127

17. Wu P, Fang Y, Guan Z, et al. The psychological impact of the SARS epidemic on hospital employees in China: exposure, risk perception, and altruistic acceptance of risk. Can J Psychiatry 2009;54:302-11.

18. McAlonan GM, Lee AM, Cheung V, et al. Immediate and sustained psychological impact of an emerging infectious disease outbreak on health care workers. Can J Psychiatry 2007;52(4):241-247. doi:10.1177/070674370705200406
19. Harvard Business Review [Internet]. What hospitals overwhelmed by Covid-19 can learn from startups. Accessed June 13, 2020. Available from: https://hbr.org/2020/05/what-hospitals-overwhelmed-by-covid-19-can-learn-from-startups

20. Ward PR. Improving access to, use of, and outcomes from public health programs: The importance of building and maintaining trust with patients/clients. Front Public Health 2017;5:22. doi: 10.3389/fpubh.2017.00022 